\title{
Exercise is medicine
}

$\mathrm{W}$

hat is the one intervention that can prevent and treat dozens of diseases? The simple answer is exercise. The complicated part is how to get people to do it. A group of Canadian health care professionals is working on solutions.

The initiative, Exercise is Medicine (EIM), started by the American College of Sports Medicine (ACSM) and the American Medical Association (AMA) in 2007 , is "calling on all health care providers to assess and review every patient's physical activity program at every visit."

Dr. Brian MacIntosh of the Canadian Society for Exercise Physiology brought EIM to Canada a year ago. The seven-member Canadian task force has set three goals: to increase the number of health care professionals who assess and counsel patients about physical activity and prescribe physical activity to their patients; to increase the number of Canadians meeting the Canadian Physical Activity Guidelines; and to encourage the appropriate use of qualified exercise professionals in preventing and treating chronic disease.

The EIM Canada Task Force is still in the brainstorming phase, Susan Yungblut, task force manager, told $C M A J$, and members are highly engaged and enthusiastic about the initiative's future. Task force members include representatives from the Canadian Society for Exercise Physiology, the College of Family Physicians of Canada, the Canadian Academy of Sport and Exercise Medicine, the Canadian Physiotherapy Association, the Dietitians of Canada, the Canadian Society for Psychomotor Learning and Sport Psychology and one clinical exercise professional.

One of the task force's first projects is to develop an educational program for physicians. Yungblut said, "We really want to ... help physicians understand how to make the best use of their limited time in the clinic, with their patients, to provide a physical activity intervention."

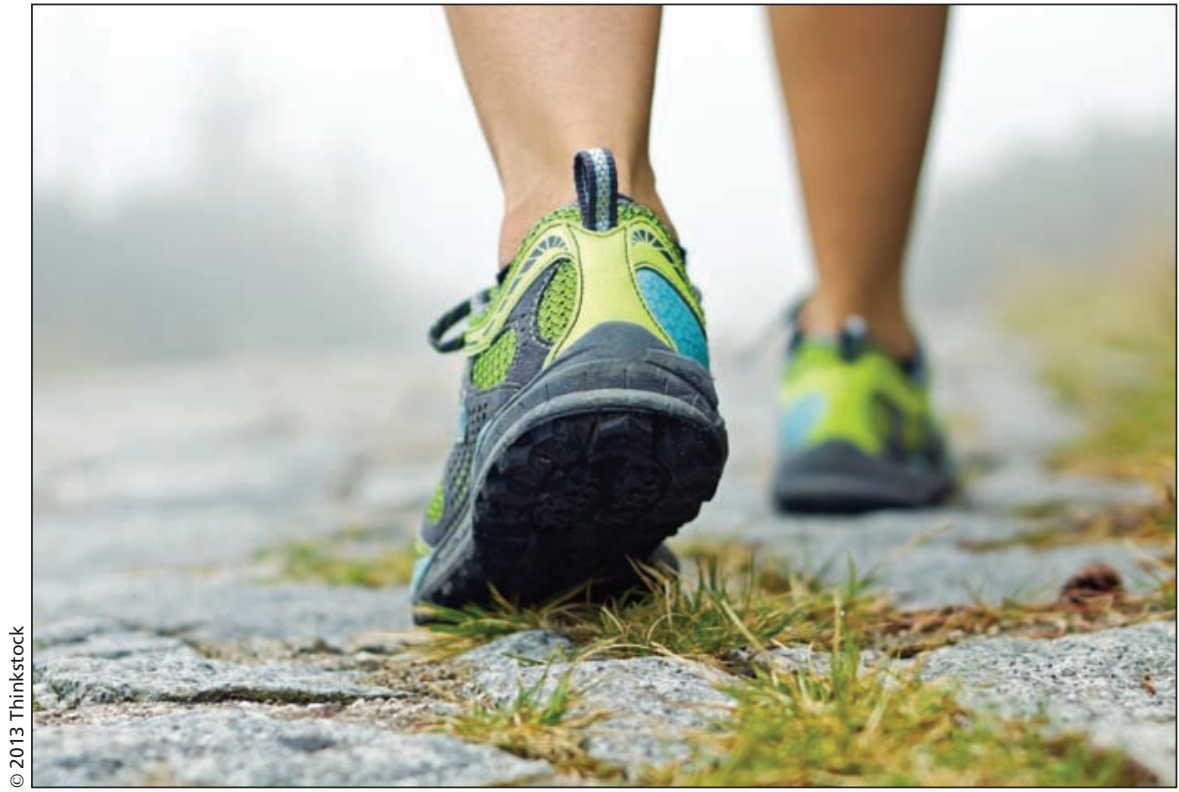

Only $5 \%$ of Canadian adults meet the Canadian Physical Activity Guidelines recommendations.

The group is using the term intervention very broadly. It could be as simple as a health care professional taking a few moments to say, "How often are you exercising?" or "How often are you physically active?" says Yungblut.

The Canadian Physical Activity guidelines recommend that adults (1864 years) get a minimum of 150 minutes of moderate- to vigorous-intensity aerobic physical activity per week. But according to the Canadian Health Measures Survey (2007/2009), the percentage of Canadians actually meeting these requirements on a regular basis is 5\%.

Task force members Drs. Pierre Fremont and Renata Frankovich recently led a workshop on EIM at the Canadian Academy of Sport and Exercise Medicine Annual Scientific Meeting in Whistler, BC. They outlined the EIM Canada initiative and reviewed how to prescribe exercise and incorporate counseling to change patient behaviour. The speakers emphasized the dissociation between fitness and weight loss as physical activity is independently associated with health benefits, regardless of its effect on weight.
Dr. Danielle Braidwood, a sports medicine physician, who attended the workshop said, "I think it's great - especially as a resource for family doctors who don't necessarily have the resources or comfort with prescribing exercise."

After years of researching the effects of integrating kinesiologists into the primary health care team, Dr. Michelle Fortier, a physical activity psychology scientist and professor at the University of Ottawa in Ontario, has joined the task force. Kinesiologists are increasingly being called upon in the clinical setting, she says. Currently, she knows of eight kinesiologists working as part of family health teams in the Ottawa area.

EIM is rapidly spreading around the globe; there are 31 national task forces from Argentina to Germany to Thailand. World congresses have been held since 2010.

The Coca-Cola Company provided seed funding to get the EIM project underway in Canada. EIM Canada is now funded by the Canadian Society for Exercise Physiology. — Erin Russell, CMAJ

CMAJ 2013. DOI:10.1503/cmaj.109-4501 